\title{
A Institucionalização da Coordenação Pedagógica na Educação da Infância em São Caetano do Sul
}

\author{
The Institutionalization of Pedagogical Coordination in Sao Caetano do Sul Childhood Education
}

La Institucionalización de la Coordinación Pedagógica en la Educación de la Infancia en São Caetano do Sul

Nonato Assis de Miranda - Universidade Municipal de São Caetano do Sul - USCS | Programa de Pós-Graduação em Educação | São Caetano do Sul | SP | Brasil. E-mail: mirandanonato@ uscs.edu.br

Renata Maria Sobral - Secretaria Municipal de São Caetano do Sul - USCS | CECAP | São Caetano do Sul | SP | Brasil. E-mail: resobra103@gmail.com

Resumo: Esta pesquisa, de natureza qualitativa, analisou a atuação do Professor Auxiliar de Direção (Proaudi) nas escolas de educação infantil de São Caetano do Sul, no estado de São Paulo, a qual se revelou ligada à coordenação pedagógica. Os dados, obtidos por meio de entrevista semiestruturada e tratados na perspectiva da teoria fundamentada, conduziram a resultados que sinalizam que os Proaudi desenvolvem um trabalho efetivo de formação de professores e de acompanhamento da aprendizagem das crianças das escolas de educação infantil. Foi constatado também que os Proaudi, por vezes, realizam tarefas inerentes aos aspectos administrativos da gestão escolar, tal como ocorre com os coordenadores pedagógicos, mas, em volume bem menor quando comparada à dimensão pedagógica. Contudo, apesar da institucionalização do Proaudi entre os professores e gestores das escolas de educação infantil, a função não é regulamentada, motivo pelo qual a escolha dos candidatos se dá pela indicação dos diretores de escola, cujos critérios não são definidos previamente.

Palavras-chave: Educação infantil. Coordenador pedagógico. Professor auxiliar de direção. Formação de professores.

Abstract: This research, of a qualitative nature, analyzed the performance of the Assistant Professor of Management (Proaudi) in the schools of early childhood education in São Caetano do Sul, in the state of São Paulo, which was shown to be linked to pedagogical coordination. The data, obtained through a semi-structured interview and treated in the perspective of the grounded theory, led to results that indicate that the Proaudi develop an effective work of teacher training and follow up of the learning of the children of the nursery schools. It was also found that the Proaudi sometimes perform tasks inherent to the administrative aspects of school management, as occurs with the pedagogical coordinators, but in a much smaller volume when compared to the pedagogical dimension. However, despite the institutionalization of Proaudi among teachers and managers of kindergartens, the function is not regulated, which is why the choice of candidates is indicated by the directors of schools whose criteria are not previously defined.

Keywords: Early childhood education. Pedagogical coordinator. Assistant professor of management. Teacher training.

Resumen: Esta investigación, de naturaleza cualitativa, analizó la actuación del Profesor Auxiliar de Dirección (Proaudi) en las escuelas de educación infantil de São Caetano do Sul, en el estado de São Paulo, la cual se reveló ligada a la coordinación pedagógica. Los datos, obtenidos por medio de entrevistas semiestructuradas y tratados en la perspectiva de la teoría fundamentada, condujeron a resultados que señalan que los Proaudi desarrollan un trabajo efectivo de formación de profesores y de acompañamiento del aprendizaje de los niños de las escuelas de educación infantil. Se constató también que los Proaudi, a veces, realizan tareas inherentes a los aspectos administrativos de la gestión escolar, tal como ocurre con los coordinadores pedagógicos, pero, en volumen mucho menor cuando se compara a la dimensión pedagógica. Sin embargo, a pesar de la institucionalización del Proaudi entre los profesores y gestores de las escuelas de educación infantil, la función no está regulada por lo que la elección de los candidatos se da por la indicación de los directores de escuela cuyos criterios no se definen previamente. 1

Palabras clave: Educación infantil. Coordinador pedagógico. Profesor auxiliar de dirección. Formación de profesores.

- Recebido em 28 de dezembro de $2018 \cdot$ Aprovado em 29 de abril de $2019 \bullet$ e-ISSN: 2177-5796

DOI: http://dx.doi.org/10.22483/2177-5796.2019v21n2p559-582

Copyright @ 2019. Conteúdo de acesso aberto, distribuído sob os termos da Licença Internaonal da CreativeCommons - CC BY-NC-SA Atribuição Não Comercial (https://br.creativecommons.org/licencas/) - Permite distribuição e reprodução, desde que atribuam os devido créditos à publicação, ao autor(es) e que licenciem as novas criações sob termos idênticos. 


\section{Introdução}

Este artigo insere-se em uma pesquisa realizada entre os anos de 2016 e 2017, no Programa de Pós-Graduação em Educação - Mestrado Profissional - da Universidade Municipal de São Caetano do Sul (SCS), intitulada O trabalho do Professor Auxiliar de Direção (Proaudi) na educação Infantil do município de São Caetano do Sul (SOBRAL, 2018), que analisou a atuação dos Proaudi nas escolas municipais de educação infantil (EI) do município citado, região do Grande ABC paulista.

Um dos motivos que justifica a realização desta pesquisa é que, apesar de o coordenador pedagógico exercer um papel significativo nas escolas de educação infantil, até 2011, as escolas desse nível de ensino de SCS não contavam com esse profissional. Isso acontecia porque nesse município não existia a função e nem tampouco o cargo de coordenador pedagógico para atuar nas escolas de EI.

Em face ao exposto, os diretores das escolas de EI de SCS queixavam-se, com frequência, à Secretaria Municipal de Educação (SME) sobre a necessidade de haver um profissional para auxiliá-los no cotidiano escolar, especialmente na dimensão administrativa. Essa reivindicação estava atrelada às demandas da gestão escolar, bem como à preocupação com a obrigatoriedade de se garantir a formação continuada dos professores de suas escolas.

Neste contexto, o Proaudi surgiu, nesta rede municipal de ensino, atendendo a uma reivindicação dos diretores das escolas de EI. Contudo, a intenção à época era que este profissional atuasse oferecendo auxílio ao diretor da escola, em tudo o que fosse necessário e não obrigatoriamente na coordenação pedagógica. Assim, não foi estabelecido, de maneira clara, o que cada um destes profissionais (diretores e Proaudi) deveria realizar no desempenho de suas funções.

Esta indefinição de papéis, por sua vez, teve reflexos na aceitação do trabalho do Proaudi por parte dos docentes das escolas, gerando algumas indagações. Dentre outras coisas, questionavam: quem seria responsável pela dimensão administrativa da gestão escolar? Quem responderia pela condução do trabalho pedagógico? Ou ainda, estariam as duas dimensões sob a responsabilidade tanto do Diretor quanto do Proaudi? 
Diante do exposto, este estudo, além de analisar a atuação desse profissional nas escolas de EI de SCS, mapeou as atribuições dos Proaudi com vistas à elaboração de uma Minuta de Lei, propondo à SME a regulamentação dessa função.

Este artigo está organizado em cinco partes. Além da introdução e das considerações

finais sobre a pesquisa, na segunda seção empreendeu-se uma breve discussão sobre a coordenação pedagógica na educação da infância. Posteriormente, apresenta-se o percurso metodológico escolhido para realizar a pesquisa e, a seguir, são apresentados os resultados, bem como as categorias analisadas na perspectiva na teoria fundamentada.

\section{A Coordenação pedagógica na educação da infância}

Embora esta pesquisa tenha como objeto de estudo a atuação dos Proaudi nas escolas de EI do município de SCS, cujas atribuições têm caminhado no sentido de coordenação pedagógica, sabe-se que, historicamente, a figura do coordenador pedagógico (CP) tem sido desenhada com frequência expressiva nas configurações das escolas de ensino fundamental.

É oportuno destacar que, diferentemente do que ocorre no ensino fundamental, na educação infantil nem todos os municípios instituíram o cargo ou função de CP. Em razão disso, há uma indefinição muito grande acerca do papel e das atribuições do coordenador da educação da infância.

Com relação à formação inicial do $\mathrm{CP}$, apesar de a Lei de Diretrizes e Bases (LDB) (BRASIL, 1996) detalhar as áreas de atuação dos profissionais da educação (Diretor de Escola, Orientador Educacional, Supervisor de Ensino, dentre outros), não especifica se o coordenador pedagógico está inserido nesse grupo de profissionais.

Não obstante, por entender que a supervisão de ensino se dá nos níveis central (Secretaria da Educação) e local (escola), parte-se do pressuposto de que o Supervisor de Ensino atua no âmbito central e o CP em nível local. Desse modo, subentende-se que a LDB, por meio de seu artigo 64 que trata da formação dos profissionais da educação, indiretamente, contempla a formação do CP.

Em 2006, a Lei Federal n 11.301 alterou o artigo 67 da LDB no 9.394/1996 e citou o termo "coordenação pedagógica" ao enumerar as funções de magistério. Longe de ser um movimento de valorização da função, esta alusão se deu somente para estabelecer quais eram os profissionais que teriam direito à aposentadoria especial (BRASIL, 2006). 
Assim, não existe uma unidade nas determinações para a função do $\mathrm{CP}$, cabendo a cada sistema ou instituição, em território nacional, estabelecer a regulamentação do trabalho deste profissional. A rede estadual de ensino de São Paulo, por exemplo, especifica a existência do professor coordenador e, por meio da Resolução SE no 75 (SÃO PAULO, 2014), enumera as suas atribuições que convergem para a dimensão pedagógica da gestão escolar.

De modo similar, alguns municípios como São Paulo, Decreto n ${ }^{\circ}$ 54.453/2013 (SÃO PAULO, 2013) e São Bernardo do Campo, Lei Municipal nº 6.372/2014 (SÃO BERNARDO DO CAMPO, 2014), na região do ABC Paulista, onde se insere o município de São Caetano do Sul, também regulamentaram o exercício da função do coordenador pedagógico por meio de leis próprias.

Nota-se, portanto, que em alguns municípios já se observa o reconhecimento da importância do coordenador pedagógico nas escolas. Não obstante, é fundamental que outros municípios busquem esta regulamentação, em um movimento de valorização desses profissionais.

Ao longo da pesquisa que originou este artigo, foram analisadas as experiências de algumas localidades brasileiras no que diz respeito à coordenação pedagógica na educação infantil, com o intuito de traçar um paralelo com o caso do Proaudi no contexto da educação infantil de São Caetano do Sul.

No caso da rede municipal de Florianópolis, na região Sul do Brasil, por exemplo, cujo atendimento em educação infantil foi, desde o início, vinculado à pasta da educação e não a cargo “[...] das Secretarias ou serviços de assistência (WALTRICK, 2008, p. 56), a dimensão pedagógica apresentou-se como fator importante no que diz respeito à caracterização do trabalho da gestão escolar. Segundo Waltrick (2008), supervisoras realizavam o trabalho de coordenação pedagógica nas unidades escolares e o caráter assistencialista que predominava na rede municipal (embora a educação infantil tivesse seu vínculo com a educação formal), que buscava suprir lacunas provenientes de estruturas familiares deficitárias, cedeu lugar gradativamente a um olhar voltado para o desenvolvimento das crianças, afastando-se aos poucos da ideia de educação compensatória.

Além de Florianópolis (WALTRICK, 2008), foram realizados estudos para analisar a coordenação pedagógica na educação infantil em Goiânia (ALVES; BARBOSA, 2011), no estado de Goiás, em Blumenau (SCHREIBER, 2011), no estado de Santa Catarina, em Araçatuba 
MIRANDA, Nonato Assis de; SOBRAL, Renata Maria. A Institucionalização da Coordenação Pedagógica na Educação da Infância em São Caetano do Sul.

(MENDES, 2012), no interior de São Paulo, na capital paulista (SÃO PAULO, 2013), no estado de São Paulo, em Niterói (GARCEZ, 2014), no Rio de Janeiro, em São Bernardo do Campo (MOYANO, 2015), na região do ABC Paulista e em Belo Horizonte (TEIXEIRA, 2015), Minas Gerais.

Um aspecto interessante desta análise é que algumas das redes investigadas, inicialmente, contavam com o trabalho do coordenador pedagógico, mas sob a perspectiva de um trabalho supervisivo, na intenção maior de verificar as ações dos professores. Este olhar era representativo de boa parte das experiências em coordenação no Brasil, até aproximadamente a década de 1950, quando a ação do supervisor passou a ter o currículo como centro de suas ações, embora numa visão tecnicista (ALVES; BARBOSA, 2011). Tal postura era responsável pelo afastamento da instituição escolar como protagonista de seu planejamento, pois entregava às instâncias superiores a tarefa da elaboração do currículo, por exemplo. Nesses termos,

\begin{abstract}
A crítica a essa forma de atuação que fragmenta a prática educativa, hierarquiza os profissionais e expropria o professor de seu saber, conduziu à busca de ressignificação da função, dentro e fora do campo da supervisão escolar, como evidenciam estudos da área. Essa busca possibilitou o surgimento da função de coordenação pedagógica em vários sistemas de ensino, suprimindo os cargos de supervisor escolar e orientador educacional, de modo articulado ao movimento de educadores, sob a liderança da Associação Nacional pela Formação dos Profissionais da Educação - ANFOPE, e de diversas instituições de ensino superior que reformularam seus cursos de Pedagogia, extinguindo as habilitações e assumindo a docência como eixo da formação e atuação do pedagogo (ALVES; BARBOSA, 2011, p. 6).
\end{abstract}

No Brasil, um questionamento acerca da formação oferecida pelo curso de Pedagogia começou a delinear-se na década de 1980, bem como quanto à postura controladora e supervisiva do profissional de Pedagogia (ALVES, 2007). Este movimento estava em curso na rede municipal de Goiânia, onde as discussões apontavam para a necessidade de uma ação mais democrática do então supervisor escolar.

Segundo Alves (2007), a partir de 1994, surge a figura do coordenador pedagógico, em substituição ao orientador educacional e ao supervisor escolar. As funções de supervisão e orientação, neste caso, ainda seriam mantidas, mas, a partir de então, na perspectiva de ações mais reflexivas sobre as questões da própria escola e com o objetivo de integrar os professores nos planejamentos. Por ocasião da realização deste estudo, foi constatado que existe, nesta rede de ensino, um regimento que explicita as funções principais deste profissional. 
MIRANDA, Nonato Assis de; SOBRAL, Renata Maria. A Institucionalização da Coordenação Pedagógica na Educação da Infância em São Caetano do Sul.

A experiência de São Bernardo do Campo, município vizinho à SCS e também integrante da Região do Grande ABC Paulista, traz uma informação especialmente relevante, pois trata-se de uma rede inserida numa realidade muito próxima à de São Caetano do Sul no que diz respeito ao aspecto geográfico.

São Bernardo do Campo é um município que sofreu forte influência do crescimento industrial. Em razão disso, muitas mulheres passaram a trabalhar fora de casa para contribuir com a renda mensal e, como não tinham com quem deixar os filhos, surgiu a demanda por vagas em creches e pré-escolas (MOYANO, 2015). Assim, o atendimento escolar na educação infantil neste município, cujo início deu-se na década de 1960, é marcado por uma tendência fortemente assistencialista no atendimento às crianças pequenas.

Cumpre destacar que, pela ausência de regulamentação, em São Bernardo do Campo, a exemplo do que ocorria em outros municípios brasileiros, para atuar na educação infantil, nesse período, não se exigia formação profissional específica. Bastava ser do sexo feminino e ser mãe para poder candidatar-se à vaga de monitora, como eram chamadas as profissionais que atuavam, diretamente, com as crianças, naquela época (MOYANO, 2015).

Na década de 1980, as creches passaram a fazer parte do Departamento de Educação assumindo o compromisso da busca de seu reconhecimento como instituições voltadas à aprendizagem das crianças. Contudo, para dar conta dessa empreitada, os gestores das creches tiveram que enfrentar muitos obstáculos. Por exemplo, a educação infantil passou a contar com formação profissional somente a partir de 1998 e, com o apoio pedagógico, na própria unidade, em 2008, ou seja, dez anos mais tarde (SOBRAL, 2018).

É oportuno mencionar que o curso de Pedagogia forma docentes e coordenadores pedagógicos, mas não os prepara para a condução de ações formativas nas escolas (MOYANO, 2015). Dada a especificidade do trabalho do coordenador, entendemos que:

Essa formação necessitaria levar em conta que esse profissional precisa ter competência para articular, formar e transformar, diferentemente do professor, cuja especificidade é o ensinar. Logo, visto que o objeto de ação do CP é diferente daquele do professor, a formação para a docência não garante o desenvolvimento de habilidades e competências para o exercício da coordenação pedagógica. Ter clareza a esse respeito contribuiria para a constituição da identidade profissional do $\mathrm{CP}$, tendo em vista que a diferenciação entre as duas funções seria objeto dos cursos de formação, o que possibilitaria identificações com aspectos específicos da função (PLACCO; ALMEIDA; SOUZA, 2011, p. 36). 
MIRANDA, Nonato Assis de; SOBRAL, Renata Maria. A Institucionalização da Coordenação Pedagógica na Educação da Infância em São Caetano do Sul.

Adicionalmente, Moyano (2015) destaca a necessidade de se realizar ações de formação continuada com o objetivo de se promover a autonomia dos docentes, valorizando os saberes de cada profissional e estruturando uma configuração de formação que não se baseie em pacotes prontos, sem flexibilidade ou atendimento às demandas específicas da rede.

Portanto,

O trabalho do coordenador com os professores, envolvendo reflexões, deveria fazer com que a ideia de autoria - fazer, errar, rever, mudar e decidir - fosse uma constante na vida escolar. A experiência tem indicado que, muitas vezes, os coordenadores se prendem a analisar as atitudes do professor com seus alunos, considerando padrões de referência formais e não valorizando atitudes diferentes das que pregam (CLEMENTI, 2005, p. 59$60)$.

A experiência da rede municipal de São Paulo, por sua vez, é particularmente significativa em razão de seus números, tanto em relação à estrutura disponível quanto à densidade populacional. A demanda de alunos de educação infantil é atendida em escolas da prefeitura e também por instituições conveniadas, que atuam em parceria com a Secretaria Municipal de Educação.

A rede do município de São Paulo estabelece, conforme o Decreto $n^{\circ} 54.453$, de 10 de outubro de 2013 (SÃO PAULO, 2013), as atribuições do coordenador pedagógico. De acordo com este documento, o trabalho deste profissional é voltado à formação em serviço dos professores e aos desdobramentos deste foco estabelecido.

O campo de atuação do CP nas escolas municipais de São Paulo aproxima-se da situação encontrada em SCS, com os Proaudi. Embora os coordenadores da rede municipal de São Paulo já tenham um considerável período de experiência na vivência destas práticas, ambos (CP e Proaudi) acompanham a aprendizagem das crianças de maneira efetiva. Esses profissionais atuam na articulação das propostas pedagógicas dos docentes, na formação continuada desses professores e também no apoio às ações administrativas que são a retaguarda e a relação entre o trabalho docente e o atendimento às crianças.

Na rede municipal de São Paulo, a Divisão de Orientação Técnica (DOT) realiza o trabalho de formação dos coordenadores pedagógicos, como o exposto a seguir.

A Divisão de Orientação Técnica da Educação Infantil tem entre suas propostas de ação atuar na formação continuada dos gestores pedagógicos das EMEIs e CEIs (Diretores e Coordenadores Pedagógicos) e das Coordenadorias de Educação (Supervisores e demais educadores da DOT nas Coordenadorias) focando a otimização dos tempos e espaços de aprendizagem e o Educar e Cuidar de forma indissociável, tendo a Cultura da Infância como pressuposto básico (SÃO PAULO, 2005, p. 50). 
No município de São Paulo existe a Jornada Especial Integral de Formação (JEIF), e, portanto, os coordenadores pedagógicos podem contar com esse horário específico para desenvolver ações formativas com os professores, além das práticas diárias de acompanhamento da ação docente. Neste aspecto, a cidade se encontra à frente de SCS, que teve este horário específico (denominado de HTPC) estabelecido muito recentemente e, por isso, ainda apresenta a necessidade de ajustes e de regulamentações.

\section{Método de Pesquisa}

Nesta seção serão apresentados o contexto onde da pesquisa foi realizada e o percurso metodológico utilizado para dar conta dos objetivos propostos.

\subsection{Contexto da Pesquisa}

A cidade investigada, São Caetano do Sul (SCS), é um pequeno município brasileiro de $15,3 \mathrm{~km}^{2}$, situado no estado de São Paulo, mais precisamente na região do grande ABC Paulista cuja população estimada é de 159.608 pessoas (BRASIL, 2017).

SCS tem confirmado sua liderança nacional em relação ao Índice de Desenvolvimento Humano Municipal (IDHM) tendo em vista que esse indicador tem mantido um bom ritmo de crescimento nas últimas décadas. De 1991 a 2010, o IDHM desse município passou de 0,697, em 1991, para 0,862, em 2010, enquanto o IDHM da Unidade Federativa (UF) passou de 0,578 para 0,783. Isso implica em uma taxa de crescimento de 23,67\% para o município e $35 \%$ para a UF; e em uma taxa de redução do hiato de desenvolvimento humano de 45,54\% para o município e $53,85 \%$ para a UF. É oportuno frisar que, em SCS, a dimensão cujo índice mais cresceu em termos absolutos foi educação (0,267), seguida por Longevidade e por Renda. Esse progresso seguiu a mesma direção da UF, pois a dimensão cujo índice mais cresceu em termos absolutos também foi educação (0,358), seguida por Longevidade e por Renda (ATLAS..., 2013).

Com esse resultado, SCS permanece na $1^{\mathrm{a}}$ posição entre os 5.565 municípios brasileiros segundo o IDHM sendo que, nesse ranking, o maior IDHM é 0,862 (SCS) e o menor é 0,418 (Melgaço). Comparativamente, SCS supera o IDHM paulista e o nacional em mais de pontos percentuais (ATLAS..., 2013; MIRANDA; MORAES, 2014). 
No que se refere à área de educação, consoante dados do Instituto Brasileiro de Geografia e Estatística (IBGE), a taxa de escolarização (para pessoas de 6 a 14 anos) foi de 97,4\% em 2010. Além disso, SCS tem obtido ótimos resultados em indicadores nacionais de educação. Em 2015, os alunos dos anos iniciais do ensino fundamental $(\mathrm{EF})$ da rede pública da cidade tiveram nota média de 7.2 no Índice de Desenvolvimento da Educação Básica (IDEB); para os alunos dos anos finais do EF, essa nota foi de 5.7 (BRASIL, 2017). Cabe frisar que, nesse mesmo ano, a média do IDEB nacional dos alunos dos anos iniciais do EF foi de 5,5 e dos anos finais desse mesmo nível de ensino de 4,5. Ou seja, SCS no ano de 2015 superou em $31 \%$ a média do IDEB nacional dos anos iniciais do EF e em $27 \%$ dos anos finais.

Esse ritmo de crescimento foi mantido na última avaliação (2017) superando, portanto, as metas estabelecidas pelo Instituto Nacional de Estudos e Pesquisas Educacionais Anísio Teixeira (INEP) tendo em vista que o IDEB de SCS dos anos iniciais do EF nesse ano foi de 7,5 e dos anos finais desse mesmo nível de ensino de 6,2 (BRASIL, 2017; GARCIA; MIRANDA, 2017). Com esses resultados, SCS supera sua própria meta, bem como a nacional (2017) e as de 2021 quais sejam: 6,0 para os anos iniciais do EF e 5,5 para os anos finais do EF.

A rede municipal de ensino de SCS conta com 55 unidades, sendo: 16 Escolas Municipais Integradas (EMI), que oferecem Educação Infantil em período integral; 22 Escolas Municipais de Educação Infantil (EMEIs); três creches conveniadas; 20 Escolas Municipais de Ensino Fundamental (EMEF) - 07 delas oferecem ensino em tempo integral; e 03 com Ensino Fundamental e Médio (SÃO CAETANO DO SUL, 2017).

\subsection{Percurso Metodológico}

No contexto da pesquisa qualitativa, optou-se pela utilização da abordagem etnográfica, utilizando observação e entrevistas. Tal situação sinaliza, por exemplo, a presença do pesquisador no espaço de observação onde ocorrem as situações e interações entre os participantes. A utilização da etnografia na escola possibilita o aprofundamento para conhecer, entre outras coisas, a origem da escola, as concepções e as práticas dos Proaudi, a relação desses profissionais com o gestor escolar, o cotidiano das escolas de educação infantil, a relação dos Proaudi com a comunidade e sua atuação na formação de professores. Na etnografia, o pesquisador envolve-se com o local e com os grupos. Porém, apesar do envolvimento, ele cria um distanciamento pelo 
fato de não possuir as mesmas inquietações e preocupações dos indivíduos que fazem parte do contexto. Paralelamente, ele cria familiaridade com a cultura local se relacionando com o outro e com o meio e procurando compreendê-los (CRESWELL, 2014). Para esse autor, na etnografia, a observação é um procedimento para coletar dados e o pesquisador estuda imerso na realidade, selecionando e interpretando evidências. No entanto, a observação tem de ser sistemática, a partir do uso de protocolos, com controle da duração de tempo e com a realização de registros, que podem incluir falas, citações e gestos. Trata-se de um processo descritivo e reflexivo. A observação utilizada no presente estudo foi estruturada, sistematizada, planejada, controlada e individual. Os observadores se envolveram com as situações e com os eventos de cinco escolas.

Os dados provenientes das entrevistas foram analisados a partir da teoria fundamentada (CRESWELL, 2005; CORBIN; STRAUSS, 1990), uma abordagem de natureza qualitativa, indutiva, cujos resultados são provenientes das análises realizadas. Os dados deste estudo foram fragmentados com a utilização de uma investigação temática de codificação aberta. A partir disto, eles foram selecionados com o uso de códigos e descritores com o intuito de identificar as diferenças e regularidades, surgindo, a partir desse processo, as categorias do estudo (GARCIA; MIRANDA, 2017).

\section{Resultados e discussão}

O perfil traçado dos cinco Proaudi participantes da pesquisa aponta para indivíduos com idade entre 48 e 56 anos, todos contando com significativa experiência na docência da educação infantil (de 22 a 25 anos). Este inclusive foi um aspecto apontado pelas entrevistadas como essencial para uma prática de sucesso como Proaudi, pois, de acordo com elas (todas as participantes da pesquisa são do sexo feminino), tal vivência permite ao profissional conhecer melhor o âmbito de atuação do docente possibilitando o desenvolvimento de ações baseadas na empatia entre as partes envolvidas (Proaudi e docentes). Com relação ao tempo de atuação como Proaudi, foi constatado o intervalo compreendido entre 4 e 7 anos.

Embora até a seção anterior o termo Proaudi esteja precedido do pronome masculino referindo-se à função e não à pessoa em si, como todas as participantes desta pesquisa são do sexo feminino, nesta seção, ao referenciar as concepções das Proaudi, utilizar-se-á o pronome feminino para determinar o gênero. 
MIRANDA, Nonato Assis de; SOBRAL, Renata Maria. A Institucionalização da Coordenação Pedagógica na Educação da Infância em São Caetano do Sul.

Todas as entrevistadas têm licenciatura em Pedagogia, mas quatro das cinco Proaudi cursaram, também, o nível médio na modalidade normal (antigo magistério). Este curso foi apontado como uma experiência rica por uma das Proaudi entrevistada, pois se constituiu em uma vivência significativa, formada por ações voltadas à prática de sala de aula. Destacaram ainda que o acompanhamento de um parceiro mais experiente (orientador de estágio) foi um fator importante para o êxito sua formação.

Este depoimento induz a pensar que, além de uma experiência que atende a uma determinação curricular, o estágio promove:

[...] o exercício de olhar para si mesmo - de descobrir-se para, então, ver e descobrir o outro - é uma rica possibilidade. Porém, é sempre bom lembrar que, embora essa possibilidade exista para todos, isso não quer dizer que para todas as coisas se darão da mesma forma (OSTETTO, 2012, p. 130).

Por outro lado, a entrevista identificou o descontentamento de um dos Proaudi a respeito da graduação em Pedagogia. A questão do efetivo preparo para o exercício da docência na educação infantil no âmbito deste curso pode ser sintetizado na seguinte perspectiva:

[...] em razão da urgência de formação de professores para a educação infantil, pouco se discute sobre uma efetiva reformulação do curso de pedagogia - ou sua substituição por um curso específico de pedagogia da infância -, fragmentado em tantas vocações (gestão, docência em mais de um nível de escolarização...), estruturado em parcos semestres, destituído de contatos com as práticas escolares e tomado pela tendência de aligeiramento própria do empresariamento educacional (STANGHERLIM; VERCELLI; SANTOS, 2015, p. 38).

Quanto ao acesso, todas as entrevistadas chegaram à função de Proaudi após terem feito a inscrição para o exercício dessa função. Segundo as próprias Proaudi, houve, por parte da Secretaria de Educação Municipal (SME), uma seleção das professoras interessadas. Para se candidatar à vaga, a professora deveria atender a alguns critérios, tais como: ter formação em nível superior (Pedagogia), ter disponibilidade para atuar em período integral, contar com no mínimo cinco anos de docência em escolas da rede municipal, dentre outros.

A primeira turma de Proaudi assumiu a função no ano de 2011. Conforme relatado pelas entrevistadas, não havia sido definido qual seria o papel das Proaudi no âmbito da Unidade Escolar. A SME apenas informou às interessadas que elas auxiliariam a diretora no que fosse necessário, dando certo destaque ao apoio às atividades administrativas da escola. 


\subsection{Criando categorias}

Considerando-se a similaridade dos depoimentos dos participantes da pesquisa, as respostas obtidas foram agrupadas e classificadas segundo critérios previamente estabelecidos quais sejam: aderência do Proaudi com as dimensões da gestão escolar, o papel desse profissional no fortalecimento do trabalho docente e as competências requeridas para o exercício da função.

Assim, foram criadas três categorias de análise: a) dimensão administrativa ou pedagógica: mapeando a rotina do Proaudi; b) o papel do Proaudi no fortalecimento da prática docente; c) competências profissionais do Proaudi, as quais serão apresentadas e discutidas, a seguir.

\section{Categoria 1: dimensão administrativa ou pedagógica: mapeando a rotina do Proaudi}

O relato de algumas Proaudis apontou no sentido de uma certa preocupação no que diz respeito à possibilidade de suas atividades profissionais estarem mais alinhadas à dimensão administrativa da gestão, conforme o conteúdo deste depoimento: "Quando a gente começou era mais, a gente achava que era mais a parte administrativa, que a gente ia mexer mais, ajudar na... na direção, matrícula, enfim, fazer todos os... o que precisa na secretaria mesmo, né? (Entrevista - Proaudi 1).

Nota-se, neste relato, certa preocupação da professora no que tange à possibilidade de suas atividades profissionais estarem mais alinhadas à dimensão administrativa da gestão. Supõese que isso ocorra porque

\footnotetext{
A principal função desse profissional é a solução de problemas administrativos e pedagógicos articulados à performance dos alunos nas avaliações sistêmicas realizadas na escola, ação que se distingue da perspectiva teórica democrática que associa o papel desse profissional à finalidade de pensar e discutir os objetivos pedagógicos da escola em sintonia com os interesses e expectativas da comunidade escolar (SILVA; SAMPAIO, 2015, p. 972).
}

Ademais, parte das Proaudis entrevistadas apontou a grande diversidade de atribuições deste profissional. Cumpre sinalizar que a falta de uma definição clara daquilo que se espera do trabalho do Proaudi contribui para uma visão multifacetada da atuação deste profissional. As palavras de Placco, Souza e Almeida (2012), ao tratar do coordenador pedagógico, ilustram este ponto de vista: 
MIRANDA, Nonato Assis de; SOBRAL, Renata Maria. A Institucionalização da Coordenação Pedagógica na Educação da Infância em São Caetano do Sul.

[...] nota-se que, na prática, esse profissional ainda toma para si (voluntária ou involuntariamente) muitas atribuições que não são de sua exclusiva responsabilidade. É possível - e desejável - que isso ocorra devido ao fato de ser o coordenador pedagógico um profissional cuja atuação privilegia a integração entre os diferentes atores da comunidade escolar, com vistas a favorecer uma prática educativa pautada nas diretrizes estabelecidas no projeto político pedagógico - PPP - e nas normativas oficiais. No entanto, a falta de compreensão sobre limites de sua atuação, considerando-se os eixos articulação, formação e transformação, pode gerar equívocos e desvios no exercício da função coordenadora (PLACCO; SOUZA; ALMEIDA, 2012, p.766).

Contudo, a maior parte dos sujeitos entrevistados entende que é importante que o Proaudi transite entre as dimensões pedagógica e administrativa da gestão escolar, uma vez que são responsáveis por substituir a diretora da escola em situações de licença, compromissos de ordem geral e, até em razão do próprio horário de trabalho dela. Não há, portanto, como se manter alheio aos assuntos de toda natureza que compõem o cotidiano da unidade.

[...] A gente tem um trabalho mais específico com as professoras e a gente também faz alguns serviços na secretaria, mas é mais específico com as professoras, auxiliares, ajudando, orientando no que elas precisam. [...] Não, aqui na escola não sinto isso. Porque aqui, assim, é bem dividido isso. A L., secretária, ela sabe o que ela tem que fazer ali, eu sei o que eu tenho que fazer. É lógico, eu me envolvo também em algumas coisas da parte da secretaria, não sei o que..., mas não são também muitas, né. Então aqui cada uma sabe a sua função, então [...]. (Entrevista - Proaudi 1)

Considerando-se que o papel do Proaudi não se encontrava definido de modo preciso para os educadores da rede, a aceitação deste profissional e a adesão às propostas apresentadas por ele também foram dificultadas, tal como demonstram os relatos destas profissionais:

\begin{abstract}
Não, eu acredito que houve um crescimento sim, sem dúvida. Quando a gente... quando eu comecei... primeiro que eu não sabia direito a função... [...] então você... começa, mas começa meio... né, receosa, até entender tudo... então foi um começo difícil. Agora não, agora eu acho que as funções já estão mais... definidas, as professoras já entendem o que é uma Proaudi e... o que a gente precisa... fazer na escola e... elas têm a gente, pelo menos aqui, né, eu vejo assim, elas têm a gente como parceira mesmo, o que precisar vem. (Entrevista - Proaudi 2)
\end{abstract}

Para esta Proaudi, um certo desconforto sentido pelas outras professoras da escola foi o que mais chamou a sua atenção. Em suas palavras:

É assim... é... quando eu fui ser Proaudi a primeira vez, foi muito uma ques... um questionamento assim: "Ah, porque que você foi escolhida e eu não fui?" [...] Porque eu fui trabalhar numa escola com pessoas muito... mais antigas do que eu. [...] Então, elas queriam saber porque que eu que tinha escolhido e não elas. Então, ali, já come... eu já percebi que tinha um... um certo... ia bater de frente. [...] Começou com isso, eu deixei elas desabafarem. [...] Então, eu nunca tive problema com professora. (Entrevista - Proaudi 3)

Nota-se aqui não somente um problema com relação à definição de papel desse profissional na gestão escolar, mas também sua aceitação pelo corpo docente. Isso acontece 
MIRANDA, Nonato Assis de; SOBRAL, Renata Maria. A Institucionalização da Coordenação Pedagógica na Educação da Infância em São Caetano do Sul.

porque os critérios de seleção dos Proaudi para atuar nas escolas não são claros, o que gera, por vezes, desconfiança sobre sua competência para apoiar o trabalho docente.

\section{Categoria 2: o papel do Proaudi no fortalecimento da prática docente}

A criação e estabelecimento de um vínculo entre Proaudi e professoras também contribui para a aceitação da presença e do trabalho deste profissional na escola, conforme pode ser constatado neste depoimento:

[...] Hoje é, hoje a gente já tem mais experiência, já tem um pouco mais de segurança... [...] Né? Já fala as coisas com um pouquinho mais de propriedade... é aquilo que eu te falei, aquilo que eu não sei, eu tenho a humildade de falar: "não sei, vou procurar saber pra eu te passar essa informaç̧ão...". Então eu percebo que eu sou, assim, eu, eu... conquisto mesmo, conquistei as professoras, eu tenho elas próximas de mim, tá? É... tenho... aqui tem boas profissionais, né? E... eu percebo que mesmo assim, em relação a fazer alguma crítica... construtiva, né, que a gente... que eu falo que até o negativo, ele... ele é constru... ele é construtivo pra gente. [...] É... eu percebo que eu consigo atingir a professora de uma maneira ... sem impacto negativo... [...] sem ela ficar com aquela má impressão de... minha, entendeu? [...] Ó, você, eu, eu... eи percebo que eu consigo ser parceira das professoras... entendeu? [...] Não, no início era um pouco insegura, tinha um pouco de receio, né? Porque pra mim era muita novidade [...]. (Entrevista - Proaudi 4)

Analisando-se o excerto supra exposto, entende-se que houve o fortalecimento de vínculos entre Proaudi e professores, bem como entre professores de educação infantil e as crianças, cuja conexão dialoga com as ideias de Malaguzzi, quais sejam:

[...] o modo como nos relacionamos com as crianças influencia o que as motiva e o que aprendem. Seu ambiente deve ser preparado de modo a interligar o campo cognitivo com os campos do relacionamento e da afetividade. Portanto, deve haver também conexão entre o desenvolvimento e a aprendizagem, entre as diferentes linguagens simbólicas, entre o pensamento e a ação e entre autonomia individual e interpessoal. Os valores devem ser colocados em contextos, em processos comunicativos e na construção de uma ampla rede de intercâmbios recíprocos entre as crianças e entre elas e os adultos (1999, p. 77).

Contudo, se, por um lado, há estes vínculos desses profissionais com os professores, é oportuno destacar que a indefinição de papéis gerou, a priori, preocupações, na medida em que dificultou um trabalho mais efetivo deles, bem como o da diretora da unidade escolar, conforme pode ser constatado neste depoimento:

[...] No começo era tudo novo, Renata, então eu fui pra uma escola que, assim, a minha relação com os funcionários era excelente. Mas, como a diretora era acostumada a fazer tudo... [...] então, ela sentia que eu estava, ela também ficou meio assim, que...né, a questão assim: ai, o que eu faço, o que, né, o que a M. faz? Então precisou de um tempo pra gente construir essa relação. Porque ficou, assim, meio que... né... aí, o que que ela pode fazer, o que que eu... que eu vou fazer... porque na verdade, assim, foi designado, mas não... não foi ali, fala: "ó, você vai fazer isso". [...] Era pra ajudar de tudo um pouco. Entendeu? [...] Era pra ajudar tanto na parte administrativa quanto no pedagógico. (Entrevista - Proaudi 5)

Quaestio, Sorocaba, SP, v. 21, n. 2, p. 559-582, maio/ago. 2019. 
MIRANDA, Nonato Assis de; SOBRAL, Renata Maria. A Institucionalização da Coordenação Pedagógica na Educação da Infância em São Caetano do Sul.

Essa indefinição de papéis pode estar atrelada à formação acadêmica deste profissional que, embora tenha licenciatura em Pedagogia, talvez não tenha se apropriado de habilidades e de competências inerentes às dimensões pedagógica e administrativa da gestão escolar. Supõe-se que tal fato esteja atrelado à própria falta de identidade desse curso, cujas críticas têm sido recorrentes desde sua criação, mas com maior ênfase a partir da década de 1990, conforme segue:

[...] há um contingente maciço de egressos dos cursos de Pedagogia que, curiosamente, não estudaram Pedagogia (sua teoria e sua prática), pois esses cursos, de modo geral, oferecem estudos disciplinares das ciências da educação que, na maioria das vezes, ao partirem dos campos disciplinares das ciências-mãe para falar sobre educação, o fazem sem dar conta da especificidade do fenômeno educativo e, tampouco, sem tomá-lo nas suas realidades histórico-sociais e na sua multiplicidade - o que apontaria para uma perspectiva interdisciplinar e multirreferencial (PIMENTA, 1998 apud LIBÂNEO; PIMENTA, 1999, p. 245).

Em razão disso, bem como da prevalência da formação teórica em detrimento da prática, também elemento característico desse curso, o egresso vê-se obrigado a se apropriar da dimensão prática no exercício da profissão, gerando, por vezes, situações de insegurança, conforme o ocorrido com a Proaudi 5.

Feito isso, em geral, as dificuldades iniciais são superadas com o tempo. Nesse caso em específico, o vínculo com professores e com a diretora foi se constituindo paulatinamente e, assim, a regularidade do trabalho, o respeito aos conhecimentos prévios e ao histórico de vida de todos os envolvidos foram se consolidando. O depoimento transcrito a seguir corrobora este ponto de vista:

Mas ai depois a gente foi, né, criando essa... essa relação, foi tendo essa relação, né? E... eu acho que... a
mesma coisa que acontece com as professoras, acontece também com a diretora e com a Proaudi. Precisa
ter essa relação de confiança...né? É... não tem como ser diferente, não tem como você e... designar... é...
não ter, passar por esse, essa experiência de... de confiança... e isso acontece no convivio. [...] Não tem
como ser diferente, né? Não adianta eu chegar hoje aqui e falar: "ah, eu quero ser uma Proaudi, eu vou
fazer isso". Enquanto você não tiver essa relação, esse convivio... é... você não vai conseguir. (Entrevista -
Proaudi 5)

Por ocasião da realização desta pesquisa, as Proaudis entrevistadas mostraram sentir-se valorizadas e respeitadas no desenvolvimento de seu trabalho; declararam que percebem que as professoras, na maioria das vezes, compreendem a dimensão do trabalho de uma Proaudi, cuja constatação foi possível a partir deste testemunho:

[...] então você... começa, mas começa meio... né, receosa, até entender tudo... então foi um começo difícil. Agora não, agora eu acho que as funções já estão mais... definidas, as professoras já entendem o que é uma Proaudi e... o que a gente precisa... fazer na escola e... elas têm a gente, pelo menos aqui, né, eu vejo assim, 
MIRANDA, Nonato Assis de; SOBRAL, Renata Maria. A Institucionalização da Coordenação Pedagógica na Educação da Infância em São Caetano do Sul.

elas têm a gente como parceira mesmo, o que precisar vem... [...] Sim, sim, eu acho que elas respeitam bastante, elas podem, às vezes, até não concordar com alguma coisa... mas elas respeitam, entendem, que tudo tem uma hierarquia, né? Então... eu também passo por uma hierarquia... se foi solicitado que eu... né, que eu solicitei pra elas alguma coisa, elas entendem que tudo vem de uma hierarquia... e elas respeitam... [...] Procuram, procuram sempre. Eu acho que... ah, pelo menos aqui é assim: tudo o que é feito... é... a gente troca bastante ideia, elas vêm e perguntam: "Você acha que tá legal? Você acha que ... é... bacana fazer assim?" Se é o planejamento, né, que nem tem no começo do ano... elas... querem trocar ideias, o que que eu acho de fazer aquele projeto pra aquela fase, se fica bacana... (Entrevista - Proaudi 2)

Um ponto muito importante relatado pelas Proaudis diz respeito à ideia apresentada por todas as entrevistadas, que informa que a totalidade das Proaudis ouvidas realizam um trabalho efetivo de formação de professores que é o aspecto que predomina na rotina de trabalho destes profissionais. As ações formativas, segundo os relatos, têm como objetivos o crescimento profissional dos professores e o aprimoramento do exercício da docência, visando à aprendizagem das crianças.

Em relação à educação infantil,

A formação de professores de forma que estes aprendam a interagir pedagogicamente com crianças indica que os estudos sobre a infância, compreendida como categoria histórico-social que integra a criança como ator social que constrói e reconstrói seu pensamento, devem ocupar espaço importante nos cursos de licenciatura para fundamentar práticas pedagógicas construídas com as crianças, fortalecendo experiências democráticas e assumindo o compromisso com a humanização da vida. (CAMPOS, 2017, p. 155).

Foi possível observar, também, nas entrevistas, uma referência à rotina intensa e, por vezes, permeada por várias intercorrências no exercício das funções do Proaudi. Estes profissionais entendem a importância de ter uma rotina de trabalho que organize o dia a dia na instituição escolar. Porém, declararam ter dificuldades em cumpri-la devido ao grande número de variáveis que surgem cotidianamente, conforme o apontado nesse relato: "Tem horas que você fica sozinha na escola, então, você tem que resolver tanto problemas administrativos como pedagógicos". Mesmo assim, essa profissional vê um lado positivo nessa situação quando afirmou: [...] "Eu acho bom... saber de tudo. Como a diretora tem que saber, também, da parte pedagógica" (Entrevista - Proaudi 3).

Com base na análise dos resultados obtidos nas entrevistas, é possível afirmar que o papel do Proaudi vem se construindo ao longo do tempo, com a prática diária. Este crescimento profissional é fruto de parcerias entre os Proaudis e os professores, além do desenvolvimento de ações formativas baseada no atendimento às demandas da própria instituição. 


\section{Categoria 3: competências profissionais do Proaudi}

Durante as entrevistas, as Proaudi listaram as características que julgavam essenciais para o desempenho da função. A capacidade de lidar com pessoas é uma habilidade que foi apontada por todas as entrevistadas, entendida aqui como a habilidade na articulação de ações e pessoas para atingir objetivos comuns à escola. Segundo elas, as relações interpessoais constituem a base de um ambiente harmônico e dinâmico de trabalho. Em outras palavras:

[...] você saber lidar com as pessoas, ter que atrair a confiança, né, sua pra trazer junto com você, eu acho que é o principal, é o atributo maior pra depois desenvolver as outras coisas, que a partir do momento que você busca essa confiança dela, traz pra você, o trabalho se desenvolve super bem. (Entrevista Proaudi 1).

A importância do conhecimento específico para o exercício da função de Proaudi também foi apontada pelas entrevistadas. Destacaram a necessidade de um embasamento teórico e prático, relativo à docência e à aprendizagem das crianças. As Proaudis ouvidas relataram que desenvolvem um processo contínuo de atualização e julgam esta ação essencial por ser o Proaudi o profissional responsável pela formação continuada dos docentes.

A educação continuada se faz necessária pela própria natureza do saber e do fazer humanos como práticas que se transformam constantemente. A realidade muda e o saber que construímos sobre ela precisa ser revisto e ampliado sempre. Dessa forma, um programa de educação continuada se faz necessário para atualizarmos nossos conhecimentos, principalmente para analisarmos as mudanças que ocorrem em nossa prática, bem como para atribuirmos direções esperadas a essas mudanças (CHRISTOV, 2012, p. 10).

A experiência como docente é ponto essencial para o trabalho como Proaudi, de acordo com as entrevistadas. Segundo os depoimentos, o exercício prévio como professor permite que se tenha uma visão ampliada do papel do docente e possibilita ao Proaudi tomar decisões mais coerentes com a prática cotidiana.

Por fim, humildade e simplicidade foram citadas como importantes nas relações construídas no ambiente escolar. A transparência nos contatos transmite respeito, afetividade e consideração pelo grupo.

As Proaudis entrevistadas identificaram que a principal vertente do trabalho que desenvolvem é a formação de professores. Todas as Proaudis ouvidas informaram que 
MIRANDA, Nonato Assis de; SOBRAL, Renata Maria. A Institucionalização da Coordenação Pedagógica na Educação da Infância em São Caetano do Sul.

consideram escasso o tempo de que dispõem para a formação docente, que realizam na modalidade de formação continuada.

Ao tratar da própria formação continuada, as Proaudis informam que precisam investir na autoformação para estarem habilitadas a desenvolver a formação junto aos docentes de maneira mais próxima às teorias de aprendizagem, como pontua Fochi (2015).

[...] sou convicto de que é necessário ao professor ter o mais alto grau de consciência sobre sua prática pedagógica. Refletir sobre a forma que fará a intervenção - direta e/ou indiretamente durante o período que está junto às crianças nos contextos de vida coletiva - pode garantir experiências interessantes tanto às crianças quanto ao adulto. Pode também gerar um espaço de transformação e constante avaliação sobre o que é fazer escola e pedagogia para crianças pequenas (p. 153).

Tal convicção se aplica também às ações desenvolvidas pelas Proaudis nos momentos formativos com os professores. A intencionalidade deve ser o pano de fundo das intervenções destes profissionais, com o objetivo de contribuir com o desenvolvimento laboral dos docentes.

Assim, para caracterizar uma proposta educacional como intencional do ponto de vista pedagógico, torna-se necessário que o docente não realize a ação educativa como se fosse apenas uma tarefa a cumprir, nem se submeta à mera aplicação de propostas, de idéias, de técnicas, de planos ou de projetos concebidos por outros, em outros contextos. A docência é a prática na qual cada ação exige a tomada de uma decisão ou opção teórica. O exercício do magistério envolve concepções, técnicas, procedimentos, instrumentos, estudos e projeção de experiências. Porém, esses artefatos precisam estar incorporados nos contextos sociais, nas interpretações que o docente pode efetuar do acontecido e lançar às metas que estabeleceu para o futuro (BRASIL, 2009, p. 101).

Os sujeitos da pesquisa realizam um trabalho constante de formação continuada com as professoras da escola em que atuam. Tal formação se estabelece com maior expressividade a

partir da construção do vínculo que a Proaudi estabelece com cada professor. Desta forma, há professores em diferentes momentos profissionais, de acordo com o seu próprio ritmo e necessidades de aprendizagem. Este tipo de formação visa atingir cada um em suas particularidades, em um movimento contínuo de autoformação.

No quadro de um percurso de formação, em que esta é entendida como um processo, cada pessoa e cada profissional torna-se o sujeito da sua própria formação e é esse ponto de vista que nos permite deslocar o centro das atenções, em termos formativos, das atividades de ensino para as atividades de aprendizagem (CANÁRIO; PIRES; HADJI, 2002, p. 156).

Considerando-se esta configuração da formação de professores e a atuação das Proaudi nas escolas de educação infantil de SCS, surgem algumas questões relativas ao processo de 
MIRANDA, Nonato Assis de; SOBRAL, Renata Maria. A Institucionalização da Coordenação Pedagógica na Educação da Infância em São Caetano do Sul.

formação dos formadores de professores, quais sejam: como estes profissionais (Proaudi) constituíram-se formadores? Como se tornar um formador de professores?

Entende-se que possíveis respostas a essas indagações podem ser encontradas no percurso formativo docente, especialmente nos cursos de Pedagogia, pois todos os Proaudi têm essa licenciatura.

Quando se analisa o perfil de egresso desse curso, constata-se que não existe a intenção da Pedagogia de preparar seus alunos para o exercício efetivo da formação de professores. Esse curso forma professores para o exercício da docência na EI e nos anos iniciais do EF, bem como para atuar no campo da gestão e do planejamento educacional e escolar.

Essa característica multifacetada do desenho do curso de Pedagogia que busca abarcar uma grande diversidade de aspectos relacionados à prática pedagógica e à rotina escolar tende a não aprofundar aspectos importantes da atuação docente. Em razão disso, o que se observa é que a formação inicial em Pedagogia não dá conta do desenvolvimento de competências de seus egressos que atendam às demandas do cotidiano escolar fazendo com que, via de regra, o coordenador pedagógico tenha de assumir a responsabilidade pela formação continuada docente.

Assim, esse profissional passa a se constituir como um formador de professores na medida em que começa a desenvolver propostas de acompanhamento da prática dos professores à luz dos documentos oficiais e dos referenciais teóricos que sustentam a ação docente.

É oportuno destacar que desenvolver ações planejadas de ação - reflexão - ação em relação à prática do professor possibilita ao formador uma visão ampliada da docência, associando as propostas cotidianas às teorias pedagógicas e ao desenvolvimento infantil. Nesse momento, são criadas situações propícias à aprendizagem contínua do professor e à análise de sua própria prática, potencializando os avanços obtidos pelas crianças por meio de intervenções eficazes realizadas pelo professor.

Assim, esses Proaudis tornaram-se formadores durante a prática, desenvolvendo um processo de aprender e ensinar simultâneos por entendermos que:

Formar o professor em serviço implica que o coordenador pedagógico dialogue com ele continuamente no cotidiano da escola, lidando com emoções e sentimentos dele próprio e do professor que acompanha. Há de se concordar com a concepção walloniana de que o indivíduo é um ser inteiro, não fragmentado. Assim, essa totalidade, tanto do professor como do coordenador pedagógico deve ser considerada no processo de formação continuada que ambos vivenciam no contexto da educação infantil (ZUMPANO; ALMEIDA, 2012, p. 28). 
MIRANDA, Nonato Assis de; SOBRAL, Renata Maria. A Institucionalização da Coordenação Pedagógica na Educação da Infância em São Caetano do Sul.

Em razão do exposto, a valorização do Proaudi por meio da regulamentação da função poderá fortalecer a autonomia desses profissionais beneficiando professores das escolas de educação infantil nas ações formativas e aos alunos no processo de desenvolvimento e aprendizagem.

\section{Considerações finais}

Esta pesquisa foi realizada com o intuito de saber como o Professor Auxiliar de Direção atua nas escolas de Educação Infantil em São Caetano do Sul.

Os resultados da pesquisa mostraram uma predominância da dimensão pedagógica em detrimento da administrativa no que tange à atuação dos Proaudis nas escolas de EI de SCS. Eles são responsáveis por ações voltadas à formação de professores, ao acompanhamento das aprendizagens das crianças, bem como à articulação de ações com a equipe escolar inerentes ao atendimento às crianças e aos pais.

Cabe destacar também a parceria estabelecida entre Proaudi e direção escolar que se constitui, na concepção das próprias entrevistadas, em um fator importante para o sucesso da gestão escolar e a aprendizagem dos alunos na escola de educação infantil.

Em razão disso, chegou-se à conclusão de que as atribuições dos Proaudi se equiparam às de um coordenador pedagógico tendo em vista que nessas duas funções são realizadas tanto atividades de cunho pedagógico quanto administrativo.

Apesar da institucionalização dos Proaudis nas Escolas de EI de SCS, essa função ainda não foi regulamentada (2019) pela SME. Por isso, o processo de escolha de Proaudi continua sendo feito por meio de indicações realizadas pelos diretores de escolas da EI cujos critérios não são claros.

Para que um professor ou professora das escolas de EI de SCS possa tornar-se Proaudi é necessário que esse profissional faça sua inscrição junto à SME. Como pré-requisito, o professor deverá comprovar licenciatura em Pedagogia e experiência mínima de cinco anos nas escolas de EI. Em seguida, a SME avalia se o (a) candidato (a) apresenta um perfil profissional correspondente ao que consideram essencial para o desempenho de um trabalho de referência junto à gestão das escolas.

A falta de regulamentação da função fez com que o desenho do campo de atuação dos Proaudis, inicialmente, não tivesse contornos claros ou bem estabelecidos. Ao longo desses anos 
de atuação dos Proaudis, o trabalho de formação de professores como foco principal de atuação desses profissionais vem se fortalecendo aos poucos. Diversas ações foram desenvolvidas junto às gestoras e aos docentes das unidades escolares, para empoderar os Proaudis no papel de formadores de professores.

Além de acompanhamento da prática in loco, a equipe de formação do Centro de Capacitação dos Profissionais da Educação Dra. Zilda Arns (CECAPE), apoiada pela SME, vem desenvolvendo um trabalho formativo com os Proaudis, contribuindo de maneira fundamental para a ênfase no trabalho pedagógico desses profissionais, direcionando-os para a formação de professores no âmbito escolar.

Ainda há diversos desafios no dia a dia dos Proaudis, pois esses profissionais ainda se deparam, algumas vezes, com a resistência de alguns docentes em reconhecê-los como formadores. Nessa perspectiva, a regulamentação da função contribuiria de maneira fundamental para o fortalecimento desses profissionais como formadores de professores, rompendo com barreiras que dificultam o alcance das ações formativas junto aos docentes e permitiria ainda uma merecida valorização do trabalho dos Proaudis.

A título de contribuição a esse sistema de ensino, foi elaborada uma Minuta de Resolução, com vistas a propor à SME de SCS a regulamentação da função do Proaudi. Não obstante, embora esse documento tenha se constituído em uma proposta inovadora para a educação infantil supervisivo Essa realidade precisa ser repensada por esse sistema de ensino, pois o acompanhamento da atuação desses profissionais, bem como a análise das entrevistas levam a crer que a regulamentação da função de Proaudi representaria um ganho significativo para a educação infantil de SCS.

\section{Referências}

ALVES, N. N. de L. Coordenação pedagógica na educação infantil: trabalho e identidade profissional na Rede Municipal de Educação de Goiânia. 2007. 290f. Tese (Doutorado em Educação) - Programa de Pós-Graduação em Educação, Universidade Federal de Goiás, Goiânia, 2007.

ALVES, N. N. de L.; BARBOSA, I. G. Identidade profissional da coordenação pedagógica na educação infantil. In: SIMPÓSIO BRASILEIRO, 25,; CONGRESSO IBERO-AMERICANO DE POLÍTICA E ADMINISTRAÇÃO DA EDUCAÇÃO, 2., São Paulo. Anais [...]. São Paulo, SP: PUC/SP, 2011. Disponível em: http://www.anpae.org.br/simposio2011/cdrom2011/PDFs/ trabalhosCompletos/comunicacoesRelatos/0415.pdf. Acesso em: 26 jul. 2017. 
MIRANDA, Nonato Assis de; SOBRAL, Renata Maria. A Institucionalização da Coordenação Pedagógica na Educação da Infância em São Caetano do Sul.

ATLAS DO DESENVOLVIMETNO HUMANO NO BRASIL. São Caetano do Sul: IDHM. Disponível em: http://www.atlasbrasil.org.br/2013/pt/perfil_m/sao-caetano-do-sul_sp. Acesso em: 10 dez. 2017.

BRASIL. IBGE - Conheça cidades e estados do Brasil. Brasília: IBGE. Disponível em: https://cidades.ibge.gov.br/brasil/sp/sao-caetano-do-sul/panorama. Acesso em: 10 dez. 2017.

BRASIL. LDB - Lei $\mathbf{n}^{\circ}$ 9.394/96, de 20 de dezembro de 1996. Estabelece as diretrizes e bases da Educação Nacional. Ministério de Educação. Brasília: MEC, 1996. Disponível em: http://www.planalto.gov.br/ccivil_03/leis/L9394.htm. Acesso em: 14 jul. 2017.

BRASIL. Lei Federal $n^{0}$ 11.301, de 10 de maio de 2006. Que altera o art. 67 da Lei $n^{\circ} 9.394$, de 20 de dezembro de 1996, incluindo, para os efeitos do disposto no $\S 5^{\circ}$ do art. 40 e no $\S 8^{\circ}$ do art. 201 da Constituição Federal, definição de funções de magistério. Disponível em: https://bit.ly/2HGLcRL. Acesso em: 14 de jun. 2017.

BRASIL. Ministério da Educação. Práticas cotidianas na educação infantil - bases para a reflexão sobre as orientações curriculares. 2009. Brasília: MEC, 2009. Disponível em:

http://portal.mec.gov.br/dmdocuments/relat_seb_praticas_cotidianas.pdf Acesso em: 13 maio 2019.

CAMPOS, E. F. E. Infância e práticas pedagógicas: reflexões na formação com professores. In:

FRANCO, M. A. R. S.; GILBERTO, I. J. L.; CAMPOS, E. F. E. Práticas pedagógicas: pesquisa e formação. São Paulo: Loyola, 2017. p. 143-157.

CANÁRIO, R.; PIRES, C. M. C.; HADJI, C. Articulação entre as formações inicial e continuada de professores. In: CONGRESSO BRASILEIRO DE QUALIDADE NA EDUCAÇÃO: FORMAÇÃO DE PROFESSORES, 1.; SIMPÓSIOS [do] CONGRESSO BRASILEIRO DE QUALIDADE NA EDUCAÇÃO: FORMAÇÃO DE PROFESSORES, 1., 2002, Brasília. Anais [...]. Brasília, DF: MEC, SEF, 2002. p. 151-174. v. 1.

CHRISTOV, L. H. da S. Teoria e prática: o enriquecimento da própria experiência. In: GUIMARÃES, A. et al. $\mathrm{O}$ coordenador pedagógico e a educação continuada. São Paulo: Loyola, 2012. p. 37-40.

CLEMENTI, N. A voz dos outros e a nossa voz: alguns fatores que intervêm na atuação do coordenador. In: ALMEIDA, L. R.; PLACCO, V. M. N. S. (orgs.). O coordenador pedagógico e o espaço da mudança. 4. ed. São Paulo: Loyola, 2005. p. 53-66.

CORBIN, J.; STRAUSS, A. Basics of qualitative research: techniques and procedures for developing grounded theory. 2. ed. London: Sage Publications. 1998.

CRESWELL, J. W. Educational research: planning, conducting, and evaluating quantitative and qualitative research. New Jersey: Merrill Prentice Hall. 2005.

CRESWELL, J. W. Investigação qualitativa e projeto de pesquisa: escolhendo entre cinco abordagens. 3. ed. Porto Alegre: Penso, 2014.

FOCHI, P. Afinal, o que os bebês fazem no berçário? Comunicação, autonomia e saber-fazer de bebês em um contexto de vida coletiva. Porto Alegre: Penso, 2015.

GARCEZ, P. de A. A coordenação pedagógica na educação infantil: a formação continuada e suas implicações na construção de subjetividades docentes. Rio de Janeiro: EdUECE, 2014.

GARCIA, P. S.; MIRANDA, N. A de. A gestão escolar e a formação docente: um estudo em escolas de um município paulista. RIAEE - Revista Ibero-Americana de Estudos em Educação, Araraquara, v. 12, n. 4, p. 2210-2230, out./dez. 2017.

LIBÂNEO, J. C.; PIMENTA, S. G. Formação de profissionais da educação: Visão crítica e perspectiva de mudança. Educação \& Sociedade, Campinas, v. 20, n. 68, dez. 1999. 
MIRANDA, Nonato Assis de; SOBRAL, Renata Maria. A Institucionalização da Coordenação Pedagógica na Educação da Infância em São Caetano do Sul.

MALAGUZZI, L. História, ideias e filosofia básica. In: EDWARDS, C.; GANDINI, L.; FORMAN, G. (orgs.). As cem linguagens da criança: a abordagem de Reggio Emilia na educação da primeira infância. Porto Alegre: Artmed, 1999. p. 59-104.

MENDES, A. C. B. Coordenação Pedagógica na educação infantil: processos investigativos e formação continuada na rede de ensino de Araçatuba. In: ENDIPE- Encontro Nacional de Didática e Práticas de Ensino, 16.; 2012, Campinas. Anais [...]. Campinas, SP: E- BOOKS DO XVI ENDIPE. Araraquara: Junqueira \& Marin Editores, 2012. p. 001150-001159. v. 2.

MIRANDA, N. A.; MORAES, N. C. Avaliação de desempenho das escolas públicas da região do grande abc na perspectiva do IDEB. Interciência e Sociedade, Mogi Guaçu, v. 3, n. 1, p. 17-26, 2014.

MOYANO, J. A. O coordenador pedagógico e a formação continuada dos profissionais de creche: possibilidades e desafios. Cadernos de Educação, São Paulo, v. 14, n. 28, p. 72-89, 2015.

OSTETTO, L. E. O estágio curricular no processo de tornar-se professor. In: OSTETTO, L. E. (org.). Educação infantil: saberes e fazeres da formação de professores. 5. ed. Campinas: Papirus, 2012. p. 127138.

PLACCO, V. M. N. de S.; ALMEIDA, L. R.; SOUZA, V. L. T. O coordenador pedagógico e a formação de professores: intenções, tensões e contradições. São Paulo: Fundação Carlos Chagas/ Fundação Victor Civita, 2011.

PLACCO, V. M. N. de S.; SOUZA, V. L. T.; ALMEIDA, L. R. O coordenador pedagógico: aportes à proposição de políticas públicas. Cadernos de Pesquisa, São Paulo, v. 42 n. 147 p. 754-771, set./dez. 2012.

SÃO BERNARDO DO CAMPO. Lei no 6.372, de 15 de dezembro de 2014. Dispõe sobre o estatuto e plano de carreira da educação básica do ensino público municipal. Disponível em:

<https://bit.ly/2HWNTBU>. Acesso em: 30 jan. 2018.

SÃO CAETANO DO SUL. Educação. São Caetano do Sul: Seeduc. Disponível em:

http://www.saocaetanodosul.sp.gov.br/secretarias/educacao.html. Acesso em: 10 dez. 2017.

SÃO PAULO. Resolução SE $\mathbf{n}^{\mathbf{0}}$ 75, de 30 de dezembro de 2014. Dispõe sobre a função gratificada de Professor Coordenador. Secretaria Estadual de Educação. Disponível em:

http://siau.edunet.sp.gov.br/ItemLise/arquivos/75_14.HTM?Time=14/07/2017\%2016:50:16. Acesso em: 14 jul. 2017.

SÃO PAULO. Decreto no 54.453, de 10 de outubro de 2013. Fixa as atribuições dos Profissionais de Educação que integram as equipes escolares das unidades educacionais da Rede Municipal de Ensino. Secretaria Municipal de Educação. Disponível em: https://leismunicipais.com.br/a/sp/s/saopaulo/decreto/2013/5445/54453/decreto-n-54453-2013-fixa-as-atribuicoes-dos-profissionais-de-educacaoque-integram-as-equipes-escolares-das-unidades-educacionais-da-rede-municipal-de-ensino. Acesso em: 19 jan. 2018.

SÃO PAULO. Proposta de formação - DOT - 2005. São Paulo: SME/DOT, 2005. Disponível em http://portal.sme.prefeitura.sp.gov.br/Educ-Inf--2012-a-2009. Acesso em: 19 jan. 2018.

SCHREIBER, S. Contribuições do coordenador pedagógico na educação infantil da rede municipal de ensino de Blumenau. 2011. Monografia (Especialização em Educação, Sociedade e Cultura) Fundação Universidade Regional de Blumenau, Blumenau, 2011.

SILVA, L. G. A. da; SAMPAIO, C. L. Trabalho e autonomia do coordenador pedagógico no contexto das políticas públicas educacionais implementadas no Estado de Goiás. Ensaio: aval. pol. públ. Educ., Rio de Janeiro, v. 23, n. 89, p. 964-983, out./dez. 2015. 
SOBRAL, R. M. O trabalho do professor auxiliar de direção (Proaudi) na educação infantil do município de São Caetano do Sul. 2018. Dissertação (Mestrado em Educação) - PPGE da Universidade Municipal de São Caetano do Sul (USCS), São Caetano do Sul, 2018.

STANGHERLIM, R.; VERCELLI, L. de C. A.; SANTOS, E. Plano Nacional de Educação (PNE 20142024) e a formação inicial para a docência na educação infantil: análise exploratória de um curso de Pedagogia de uma universidade pública paulista. Eccos - Revista científica, São Paulo, n. 37, p.19-42, maio/ago. 2015.

TEIXEIRA, A. de B. A coordenação pedagógica na educação infantil em Belo Horizonte: a delimitação de suas funções e a sua efetivação no cotidiano escolar. 2015. 83f. Dissertação (Mestrado Profissional) - Programa de Pós-Graduação Profissional em Gestão e Avaliação da Educação Pública, Faculdade de Educação, Universidade Federal de Juiz de Fora, Juiz de Fora, 2015.

WALTRICK, R. E. de L. O coordenador pedagógico na educação infantil da rede municipal de educação de Florianópolis: marcas de uma experiência democrática. 2008. 178f. Dissertação (Mestrado em Educação) - Programa de Pós-Graduação em Educação, Universidade Federal de Santa Catarina, Florianópolis, 2008.

ZUMPANO, V. A. A.; ALMEIDA, L. R. A atuação do coordenador pedagógico na educação infantil. São Paulo: Loyola, 2012. 